\title{
The effect of acute illness on leucocyte and plasma ascorbic acid levels
}

\author{
BY W. J. MAC LENNAN AND JUDITH C. HAMILTON \\ Faculty of Medicine, University of Southampton, \\ Southampton General Hospital, Southampton SO9 4XY
}

\begin{abstract}
1. Serial estimations of plasma (PAA) and leucocyte (LAA) ascorbic acid concentrations were made in geriatric patients in a stable phase of their illness, and compared with a similar ('unstable') group suffering from acute illness.

2. In the 'unstable' group, though PAA levels were unchanged, LAA levels were reduced.

3. In the 'follow-up' period of 7-8 $d$ there was much greater variation in both PAA and LAA levels in the 'unstable' group.

4. Acute illness was often accompanied by an increase and then a decrease in LAA levels. Recovery was associated with an increase in LAA levels.
\end{abstract}

Elderly female patients with low leucocyte ascorbic acid (LAA) levels have an excess mortality (Wilson, Weeks, Mukherjee, Murrell \& Andrews, 1972). This is not improved by giving ascorbic acid supplements (Wilson, Datta, Murrell \& Andrews, 1973). The implication is that low LAA levels may of ten be due to a disturbance in ascorbic acid metabolism rather than to a simple dietary deficiency.

There is a considerable amount of evidence that acute illness may have an effect on blood levels of ascorbic acid. Hume, Weyers, Rowan, Reid \& Hillis (1972) have demonstrated that there is a rapid decrease in LAA concentrations over the first $24 \mathrm{~h}$ of a myocardial infarction. Levels gradually return to normal during the next 2 weeks. A similar, but less striking reduction in levels may be noted in subjects succumbing to the common cold (Hume $\&$ Weyers, 1973). The effect of surgery on increased ascorbate utilization has long been recognized (Crandon, Landau, Mikal, Balmanno, Jefferson \& Mahoney, 1958). The present communication describes an attempt to elucidate further the effect of acute illness on ascorbic acid metabolism in sick elderly subjects.

\section{METHODS}

A group of twenty-three men and twenty women admitted to a geriatric unit were investigated over periods ranging from $3 \mathrm{~d}$ to 4 weeks. The length of the 'follow-up' study was determined by the times of death or discharge from the unit. Details were recorded of diagnoses made at the start of the study and of clinical episodes occurring during its course. Conditions were classified as being acute or chronic. Those likely to produce a major deterioration or improvement in the clinical condition of the patient during the course of the study were considered to be acute; while those which had been established for some time before the start of the study and were unlikely to produce major changes during the course of it were considered to be chronic. Care was taken to ensure that this information was recorded before the results of the laboratory measurements were known.

Samples of blood were collected between 10.00 hours and 12.00 hours at 3 or 4 d intervals. On these were estimated the LAA using the method of Denson \& Bowers (1961) and plasma ascorbic acid (PAA) using the method of Roe \& Kuether (1943).

Ethical considerations. The permission of patients was sought before taking samples of blood. Wherever possible samples were taken when blood was also required for routine clinical investigations. 
Table 1. Clinical details of subjects considered to be in a stable or unstable phase of their illness when admitted to a geriatric unit

\begin{tabular}{|c|c|c|c|c|}
\hline \multicolumn{2}{|r|}{ 'Stable' group } & \multicolumn{3}{|c|}{ 'Unstable' group } \\
\hline $\begin{array}{c}\text { Subject } \\
\text { no. }\end{array}$ & Chronic illness* & $\begin{array}{c}\text { Subject } \\
\text { no. }\end{array}$ & Chronic illness* & Acute illness \\
\hline 1 & Fractured femur & 1 & Nil & Bronchopneumonia \\
\hline 2 & Osteoarthritis & 2 & Hemiparesis & Bronchopneumonia \\
\hline 3 & Fractured femur & 3 & Hemiparesis & Bronchopneumonia \\
\hline 4 & Hemiparesis & 4 & Uraemia & Enlarging pressure area \\
\hline 5 & Hemiparesis & 5 & Hemiparesis & Bronchopneumonia \\
\hline 6 & Hemiparesis & 6 & Senile dementia & Bronchopneumonia \\
\hline 7 & Hemiparesis & 7 & Osteoarthritis & Joint effusion \\
\hline 8 & Hemiparesis & 8 & Fractured femur & Infected wound sinus \\
\hline 9 & Hemiparesis & 9 & Breast cancer & Enlarging pressure area \\
\hline 10 & Hemiparesis & 10 & Hemiparesis & Bronchopneumonia \\
\hline 11 & Senile dementia & 11 & Hemiparesis & Bronchopneumonia \\
\hline 12 & Osteoarthritis & 12 & Osteoarthritis & Bronchopneumonia \\
\hline 13 & Fractured femur & 13 & Heart block & Enlarging pressure area \\
\hline 14 & Hemiparesis & 14 & Hemiparesis & Bronchopneumonia \\
\hline 15 & Undernutrition & 15 & Peripheral arteriosclerosis & Gangrene of leg \\
\hline 16 & Fractured femur & 16 & Motor neurone disease & Bronchopneumonia \\
\hline 17 & Hemiparesis & 17 & Hemiparesis & Cellulitis \\
\hline 18 & Urinary incontinence & 18 & Hemiparesis & Bronchopneumonia \\
\hline 19 & Hemiparesis & 19 & Cardiac failure & Pyrexia \\
\hline 20 & Hemiparesis & 20 & Peripheral arteriosclerosis & Gangrene of leg \\
\hline & & 21 & Cardiac failure & Enlarging pressure area \\
\hline & & 22 & Hemiparesis & Enlarging pressure area \\
\hline & & 23 & Hemiparesis & Bronchopneumonia \\
\hline
\end{tabular}

* In all cases, hemiparesis or fractured femur occurred at least 8 weeks before the inclusion of the subject in the study.

\section{RESULTS}

Surveillance of the clinical details revealed that twenty subjects were in a relatively stable phase of their illness at the start of the investigation and that their condition had remained unchanged during the course of the study. Another twenty-three subjects were either suffering from acute illness at the start of the assessment or subsequently experienced a major change in their condition. Acute and chronic conditions afflicting the subjects are listed in Table 1. Multiple pathology was common, but to simplify the Table, only one chronic disorder has been attributed to each subject. This was the one considered to be responsible for the subjects being admitted to hospital.

Table 2 details LAA and PAA levels estimated from blood samples taken from the subjects. Mean LAA values were significantly lower in the 'unstable' group than in the 'stable' group when samples were taken initially $(t 3.082,0.01>P>0.001)$ and at day 3 or day $4(t 2.484,0.02>P>0.01)$. Reduced mean LAA values were also found in samples from the 'unstable' group at day 7 or day $8(t 1.782,0.1>P>0.05)$ and at day 11 or day $12(t 1.691,0.2>P>0 \cdot 1)$, but the differences from values in the 'stable' group were not statistically significant. No differences were noted in the PAA levels of subjects in the 'stable' and 'unstable' groups. Values for LAA:PAA were significantly lower in the 'unstable' group when samples were taken initally $(t 3.431,0.01>P>0.001)$, at day 3 or day $4(t 3.455,0.01>P>0.001)$ and at day 11 or day $12(t 2.929,0.01>P>0.001)$. $A$ reduced value for $L A A: P A A$ recorded in samples taken from the 'unstable' group at day 7 or day $8(t 1 \cdot 825,0 \cdot 1>P>0.05)$ was not statistically significant.

Nineteen subjects in a 'stable' phase and nineteen in an 'unstable' phase of their illness 
Table 2. Leucocyte (LAA; nmol/10 $10^{8} \mathrm{WBC}$ ) and Plasma (PAA; nmolll) ascorbic acid levels in subjects admitted to a geriatric unit with stable and unstable clinical conditions

(Mean values and standard deviations)

\begin{tabular}{|c|c|c|c|c|c|c|c|}
\hline \multirow{2}{*}{$\begin{array}{l}\text { Period after } \\
\text { start of } \\
\text { investigation }\end{array}$} & & \multicolumn{3}{|c|}{ 'Stable' group* } & \multicolumn{3}{|c|}{ 'Unstable' group* } \\
\hline & Measurement & $\begin{array}{l}\text { No, of } \\
\text { subjects }\end{array}$ & Mean & SD & $\begin{array}{l}\text { No. of } \\
\text { subjects }\end{array}$ & Mean & SD \\
\hline Day 1 & $\begin{array}{l}\text { LAA } \\
\text { PAA } \\
\text { LAA:PAA }\end{array}$ & $\begin{array}{l}20 \\
20 \\
20\end{array}$ & $\begin{array}{l}84 \cdot 6 \\
34 \cdot 1 \\
2 \cdot 58\end{array}$ & $\begin{array}{l}26 \cdot 7 \\
15 \cdot 3 \\
0 \cdot 73\end{array}$ & $\begin{array}{l}23 \\
23 \\
23\end{array}$ & $\begin{array}{l}59 \cdot 1 \\
38 \cdot 6 \\
1 \cdot 7\end{array}$ & $\begin{array}{l}26 \cdot 7 \\
14 \cdot 8 \\
0 \cdot 89\end{array}$ \\
\hline Day 3 or 4 & $\begin{array}{l}\text { LAA } \\
\text { PAA } \\
\text { LAA:PAA }\end{array}$ & $\begin{array}{l}20 \\
20 \\
20\end{array}$ & $\begin{array}{l}82 \cdot 4 \\
32 \cdot 4 \\
2 \cdot 72\end{array}$ & $\begin{array}{l}26 \cdot 1 \\
13 \cdot 1 \\
0 \cdot 79\end{array}$ & $\begin{array}{l}22 \\
22 \\
22\end{array}$ & $\begin{array}{l}60 \cdot 2 \\
34 \cdot 6 \\
1 \cdot 85\end{array}$ & $\begin{array}{l}30 \cdot 1 \\
15 \cdot 3 \\
0 \cdot 82\end{array}$ \\
\hline Day 7 or 8 & $\begin{array}{l}\text { LAA } \\
\text { PAA } \\
\text { LAA:PAA }\end{array}$ & $\begin{array}{l}19 \\
19 \\
19\end{array}$ & $\begin{array}{l}84 \cdot 1 \\
31 \cdot 8 \\
2 \cdot 84\end{array}$ & $\begin{array}{l}26 \cdot 1 \\
15 \cdot 3 \\
0 \cdot 67\end{array}$ & $\begin{array}{l}19 \\
19 \\
19\end{array}$ & $\begin{array}{l}65 \cdot 9 \\
32 \cdot 4 \\
2 \cdot 26\end{array}$ & $\begin{array}{l}34 \cdot 6 \\
10 \cdot 2 \\
1 \cdot 17\end{array}$ \\
\hline Day 11 or 12 & $\begin{array}{l}\text { LAA } \\
\text { PAA } \\
\text { LAA:PAA }\end{array}$ & $\begin{array}{l}14 \\
14 \\
14\end{array}$ & $\begin{array}{l}93 \cdot 2 \\
36 \cdot 4 \\
2 \cdot 44\end{array}$ & $\begin{array}{l}60 \cdot 2 \\
12 \cdot 5 \\
0 \cdot 77\end{array}$ & $\begin{array}{l}12 \\
12 \\
12\end{array}$ & $\begin{array}{l}58 \cdot 5 \\
38 \cdot 1 \\
1 \cdot 57\end{array}$ & $\begin{array}{l}35.2 \\
15.9 \\
0.67\end{array}$ \\
\hline
\end{tabular}
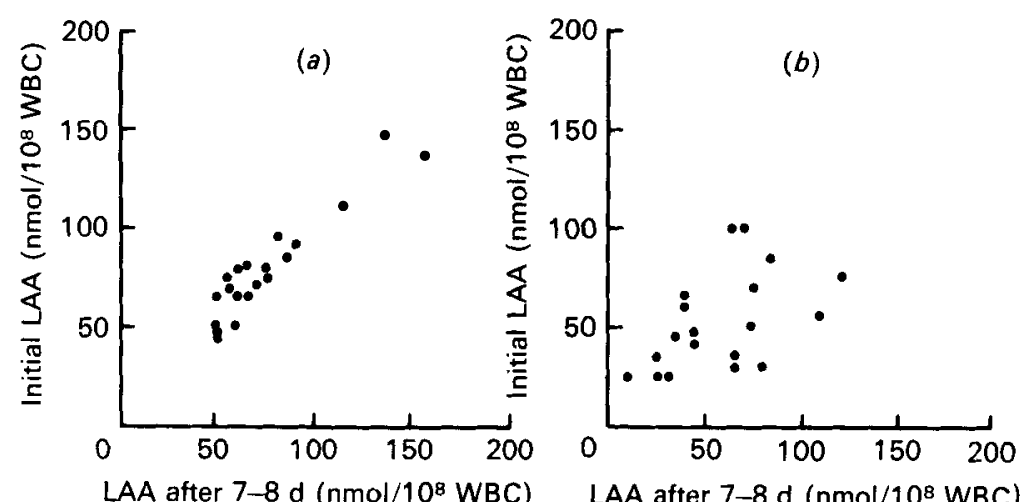

LAA after 7-8 d (nmol/108 WBC) LAA after $7-8 \mathrm{~d}\left(\mathrm{nmol} / 10^{8} \mathrm{WBC}\right.$ )

Fig. 1. Changes in leucocyte ascorbic acid (LAA) concentrations (nmol/10 $10^{8}$ white blood cells (WBC)) in subjects admitted to a geriatric unit with $(a)$ stable and (b) unstable clinical conditions. For details of groups, see Table 1.

had been 'followed up' for at least $7 \mathrm{~d}$. LAA and PAA levels estimated at the beginning of the study were compared with those values estimated 7-8 d later. Figs. 1 and 2 show that there was a much greater scatter for both LAA and PAA values in the 'unstable' group. In Table 3, negative signs have been ignored in calculating the mean positive or negative change in LAA and PAA levels in the 7-8 d period. Since values for the change in LAA values showed a marked skew to the right, these values were expressed as logs. There was a significant increase of the mean change for both LAA and PAA values in the 'unstable' group (LAA: $t 2.451,0.05>P>0.02$; PAA : $t 2.303,0.05>P>0.02$ ).

The relationship between changes in LAA levels and those in PAA levels was investigated (Fig. 3). There was a significant positive correlation between LAA and PAA values in the 'stable' group ( $n 19, r 0.578,0.01>P>0.001)$. A negative correlation between LAA and 
Table 3. Changes in leucocyte (LAA) and plasma (PAA) ascorbic acid levels in the 'follow-up' period of 7-8 $d$ in subjects admitted to a geriatric unit with stable and unstable clinical conditions

(Mean values and standard deviations)

\begin{tabular}{|c|c|c|c|c|c|c|}
\hline \multirow[b]{2}{*}{ Measurement } & \multicolumn{3}{|c|}{ 'Stable' group* } & \multicolumn{3}{|c|}{ 'Unstable' group" } \\
\hline & $\begin{array}{l}\text { No. of } \\
\text { subjects }\end{array}$ & Mean & SD & $\begin{array}{l}\text { No. of } \\
\text { subjects }\end{array}$ & Mean & SD \\
\hline $\begin{array}{l}\text { LAA }\left(\log _{10} \mathrm{nmol} / 10^{8}\right. \\
\text { WBC) }\end{array}$ & 19 & 0.505 & 0.499 & 19 & $1 \cdot 087$ & $0 \cdot 432$ \\
\hline PAA $(\mu \mathrm{mol} / \mathrm{l})$ & 19 & $6 \cdot 4$ & $5 \cdot 5$ & 19 & $12 \cdot 7$ & $10 \cdot 1$ \\
\hline
\end{tabular}

WBC, white blood cells.

* For details, see Table 1.
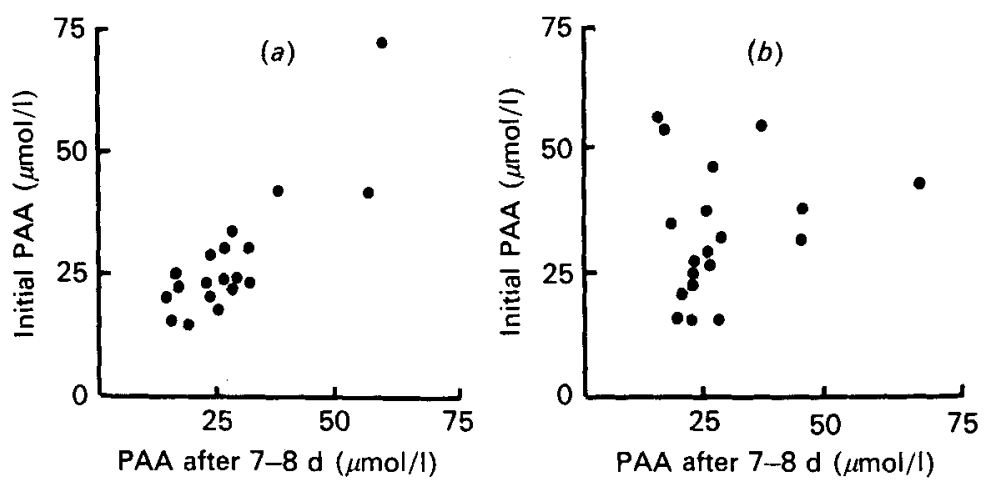

Fig. 2. Changes in plasma ascorbic acid (PAA) concentrations (nmol/l) in subjects admitted to a geriatric unit with (a) stable and $(b)$ unstable clinical conditions. For details of groups, see Table 1.

(a)

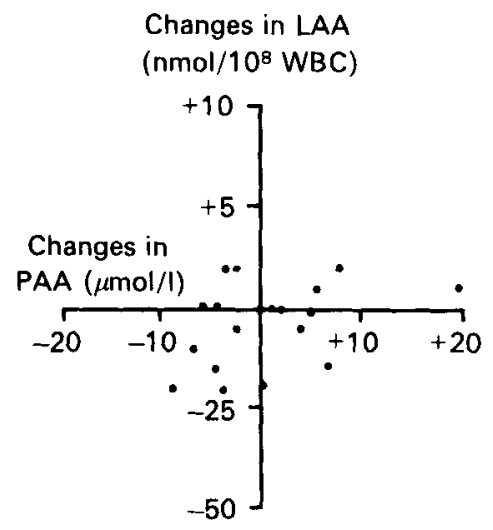

(b)

Changes in LAA (nmol/108 WBC)

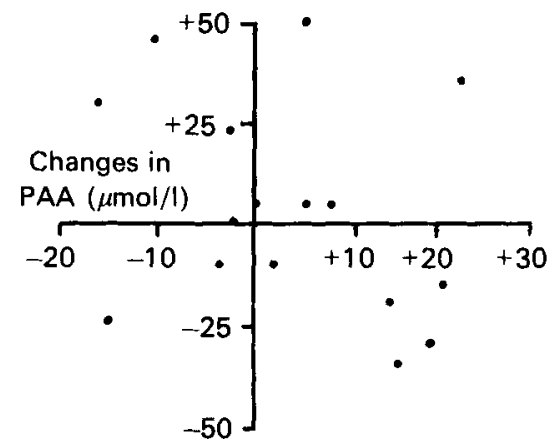

Fig. 3. Changes in leucocyte ascorbic acid (LAA) concentrations (nmol/10 $0^{8}$ white blood cells (WBC)) in a period of 7-8 d relative to those for plasma ascorbic aicid (PAA) concentrations (nmol/l) in subjects admitted to a geriatric unit with $(a)$ stable and $(b)$ unstable clinical conditions. For details of groups, see Table 1 . 

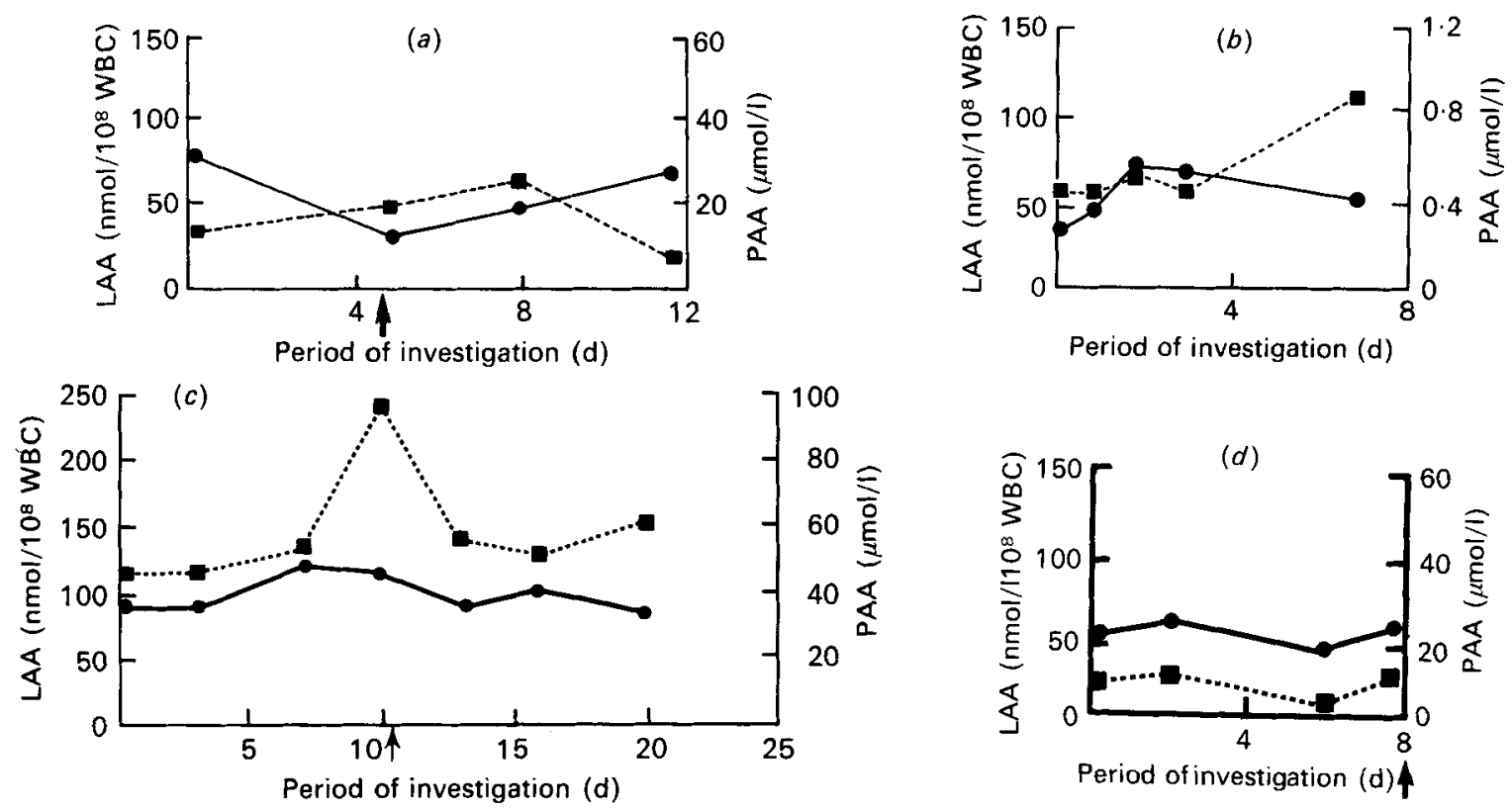

Fig. 4. Changes in leucocyte (LAA; nmol/10 $10^{8}$ white blood cells (WBC)) ( $\left.---\square\right)$ and plasma (PAA; nmol/1) (- ) ascorbic acid concentrations in individual subjects admitted to a geriatric unit with stable and unstable clinical conditions (for details, see Table 1). (a), hemiparesis, ( $\uparrow$ ) signs of chest infection, died $16 \mathrm{~d}$ after the investigation period; $(b)$, resolving bronchopneumonia; $(c)$, cardiac failure, $(\uparrow)$ pyrexia; $(d)$, peripheral gangrene, $(\uparrow)$ died.

Table 4. Patterns of leucocyte ascorbic acid (LAA) changes in individual subjects admitted to a geriatric unit with stable and unstable clinical conditions*

\section{LAA pattern}

Increase followed by steady decrease

No change (all LAA values $>50 \mathrm{nmol} / 10^{8} \mathrm{WBC}$ )

No change (all LAA values $<50 \mathrm{nmol} / 10^{8} \mathrm{WBC}$ )

Increase

Steady decrease

Steady increase

Increase then decrease to previous level

No change (all LAA values $>50 \mathrm{nmol} / 10^{8} \mathrm{WBC}$ )

No change (all LAA values $<50 \mathrm{nmol} / 10^{8} \mathrm{WBC}$ ) $\begin{gathered}\text { No. of } \\ \text { subjects }\end{gathered} \quad \begin{gathered}\text { Clinical event associated } \\ \text { with ascorbic acid changes }\end{gathered}$

Outcome 
PAA values in the 'unstable' group just failed to be statistically significant $(n 19, r 0.372$, $0 \cdot 1>P>0.05$ ).

Examination of changes in LAA and PAA levels in individual subjects revealed a variety of responses to illness (Fig. 4). In subject A, a chest infection was associated with an increase and later a decrease in the LAA levels. PAA levels on the other hand, increased and then decreased. The general condition of the patient continued to deteriorate and he died $16 \mathrm{~d}$ later. Changes noted in subject B illustrated the resolution of a bronchopneumonia in which LAA level steadily increased. There was little change in PAA levels. In subject C, a brief episode of pyrexia was associated with a marked increase in LAA levels. Changes found in subject $D$ revealed that prolonged illness may sometimes produce extremely low LAA levels. Even in this situation, however, the PAA levels remained reasonably high.

Table 4 details the changes noted in LAA levels in the 'unstable' group. For the purposes of this Table a change in LAA level of greater than $10 \mathrm{nmol} / 10^{8}$ white blood cells was considered to be significant. Nine of the twelve patients who eventually died showed either a decrease in their LAA levels or an increase followed by a decrease in these levels. A similar analysis for PAA levels was attempted but no consistent pattern emerged.

\section{DISCUSSION}

Consideration should be given to the possibility that the complex changes noted in the present study were related to the effect which illness had on dietary intake. Undernutrition is well recognized as a cause of low LAA levels (Milne, Lonergan, Williamson, Moore, McMaster \& Percy, 1971). In such a situation, however, low LAA levels are paralleled by low PAA levels (Griffiths, Brocklehurst, Scott, Marks \& Blackley, 1967). Although in our 'unstable' group the LAA level was reduced, the PAA level was the same as that for the 'stable' group. Factors other than dietary deficiency have to be called to account for these changes.

Ageing alone is associated with a decrease in LAA levels and an even greater decrease in PAA levels (Loh \& Wilson, 1971). A feasible explanation is that the decrease in LAA levels represents a reduction in the amount of ascorbic acid available for storage, while the decrease in PAA levels indicates a reduction in the amount available for metabolism by the tissues (Loh \& Wilson, 1971). Healthy elderly people have reduced metabolism which could well be responsible for a disproportionate decrease in PAA levels. In acute illness stress might have the effect of increasing the availability of ascorbic acid by displacing it from the leucocytes into the plasma. This would account for PAA levels being maintained even though in acute illness LAA concentrations are reduced. Supporting evidence for the hypothesis is to be found in studies on the common cold where leucocyte uptake of ascorbic acid from plasma was much lower during than after resolution of the infection (Wilson \& Loh, 1973).

An alternative explanation is that a reduction in the LAA concentration represents a migration of ascorbate-rich polymorphs to a site of infection or infarction followed by their replacement with immature polymorphs containing relatively low concentrations of the vitamin (Hume et al. 1972). Support for this explanation is the negative correlation between leucocyte or neutrophil polymorph counts and LAA levels; and the identification of high concentrations of ascorbic acid in burns and areas of infarction (MacLennan \& Hamilton, 1976; Barton, Laing \& Barisoni, 1972; Hume et al. 1973.) A cytochemical method of identifying ascorbic acid in leucocytes would be necessary to confirm or refute this theory.

Analysis of the present information was complicated by the fact that acute illness was often associated with an increase in LAA levels rather than a decrease in these levels. This disguised an increase associated with recovery or a decrease which might be expected to 
precede death. Accepting these limitations, however, it is clear that acute illness is responsible for considerable fluctuations in both leucocyte and ascorbic acid levels.

In a heterogeneous group of elderly people with multiple pathology any attempt to relate ascorbic acid change to clinical events must be tentative. However, certain patterns emerge. An acute illness is often associated with an increase in the LAA level. This then decreases to levels considerably lower than those originally recorded. A continued decrease in LAA levels often precedes death. Recovery is preceded by reversal of the decrease and a slow, steady increase in LAA levels returning to normal levels. If the illness has been prolonged, serial estimations may only show a consistently low LAA level. Values have already reached a nadir and can go no lower. A good example was the patient with peripheral gangrene.

No clear pattern for changes in PAA levels emerged. It should be noted, however, that whereas the mean level for LAA decreased in the 'unstable' group there was no such change in that for PAA. This suggests that even in situations of depletion, ascorbic acid was being directed from intracellular stores into the plasma to meet the demands of increased tissue metabolism. Again, while in the 'unstable' group the negative correlation between LAA and PAA levels were not statistically significant, this contrasted strongly with the high positive correlation between the two measurements in the stable group. An interpretation of this might be that in the 'stable' group fluctuations in LAA and PAA levels were related to diet. In the 'unstable' group a complex metabolic flux between leucocytes and plasma abolished this relationship.

This paper provides evidence that LAA levels are highly sensitive to the state of health of a patient. It supports the findings of Wilson et al. (1973), that patients with low LAA levels have an excess mortality and that this excess can be particularly related to those subjects whose LAA levels fail to respond to ascorbic acid supplements. These conclusions were, perhaps, anticipated by Lind (1753) (quoted by Meiklejohn, 1953). He emphasized that although orange juice cured scurvy, the condition itself was intimately related to the cold, damp, infections, fatigue, discontent and alcohol, factors associated with a life at sea. In situations of stress depletion may be a marker rather than a cause of disease.

The authors are grateful for the advice and encouragement we received from Professor K. G. M. M. Alberti and Professor M. R. P. Hall during the course of this investigation.

\section{REFERENCES}

Barton, G. M. G., Laing, J. E. \& Barisoni, D. (1972). Int. Z. VitamForsch. 42, 524.

Crandon, J. H., Landau, B., Mikal, S., Balmanno, J., Jefferson, M. \& Mahoney, S. (1958). New Engl. J. Med. 258, 105.

Denson, K. W. \& Bowers, E. (1961). Clin. Sci. 21, 157.

Griffiths, L. L., Brocklehurst, J. C., Scott, D. L., Marks, J. \& Blackley, J. (1967). Geront. Clin. 9, 1.

Hume, R. \& Weyers, E. (1973). Scott. med. J. 18, 3.

Hume, R., Weyers, E., Rowan, T., Reid, D. S. \& Hills, W. S. (1972), Br. Heart J. 34, 238.

Loh, H. S. \& Wilson, C. W. M. (1971). Br. med. J. iii, 733.

MacLennan, W. J. \& Hamilton, J. C. (1976). Age and Ageing 5, 43.

Meiklejohn, A. P. (1953). Vitams Horm. 11, 61.

Milne, J. S., Lonergan, M. E., Williamson, J., Moore, F. M. L., McMaster, R. \& Percy, N. (1971). Br. med. $J$, iv, 383.

Roe, J. H. \& Kuether, C. A. (1943). J. biol. Chem. 147, 399.

Wilson, C. W. M. \& Loh, H. S. (1973). Lancet i, 638.

Wilson, T. S., Datta, S. N., Murrell, J. S. \& Andrews, C. T. (1973). Age and Ageing 2, 163.

Wilson, T. S., Weeks, M. M., Mukherjee, S. K., Murrell, J. S. \& Andrews, C. T. (1972). Geront. Clin. 14, 17. 